\title{
Understanding the bureaucratic mind - an analysis of Homo bureaucraticus
}

A s surgeons, we live in bureaucratic environments. To survive and prosper, these few observations are offered as a way to probe and survive this mindset.

The bureaucratic mind has two needs: to achieve the financial goal set for it, and to keep being employed. With employment comes a pension, perks, status, a title and the chance to move up in the organization.

The bureaucratic mind is akin to the legal mind. Both believe in the supremacy of rules. The legal mind calls these laws; the bureaucratic mind, well, rules. Both minds believe that without rules other humans not gifted with their insight into human nature would go off the rails and descend into anarchy. Neither believe that individuals can govern themselves with few rules or that training produces autonomy. Much time is spent devising rules for every situation. Both minds have deeply pessimistic views of human nature and its ability to self direct and learn, and believe rules are written to make life easier for everyone, and to ease the burden of thinking.

\section{Conformity and egality run on rules}

The bureaucratic mind understands that once a rule is in place it applies to everyone. An exception would destroy the rule. The bureaucratic mind requires many helpers to carry out tasks as bureaucratic work expands and work must be spread over a broad base.

Simpler jobs must be delegated. The bureaucratic mind makes the major decisions and spreads responsibility. No decision is seen to be taken unilaterally to avoid criticism; instead, decisions (most of which have already been made) are made by group dynamics and group problem-solving meetings that are directed to the conclusion. This is necessary because few want responsibility but many need to be heard. "This is what you should do" is a refrain at these meetings.

The key to working with this mindset is to understand its flaws and needs because certain things are incompatible with it. This system, although streamlined and open, is not very innovative and those wanting to do more work than average are seen as being disruptive and threatening to the common agreed-upon standard.

\section{Rules reduce productivity but increase predictability}

This mindset can be studied like an exotic species. To study it, realize what the mind needs and do not threaten it. It will soon be unable to solve problems without considering more than one solution. You will learn how the mind works and what its deficiencies are. There is no need to fear becoming bureaucratic by exposure any more than the bureaucrat will become like you but one needs to be able to cover up reactions to its more outrageous rules and proclamations as it senses agnostics to its control. It does not debate.

An epiphany comes when you realize you do not need bureaucrats but can simply observe the type as a personal survival mechanism. Do

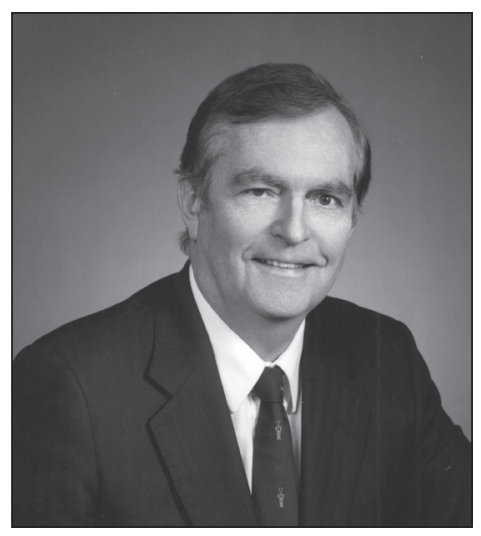
not let it know it is under observation. It is very wary.

Also, the bureaucratic mind needs sameness and conformity, so it is mind-numbingly slow. That is one of its weaknesses; it is fearful of change and protective of the status quo.

The bureaucratic mind believes the title is more important than the work done and keeps its position while reducing the actual work performed. Successful bureaucrats are those who can adapt to what is asked of them. Soon they have few other influences as those who question and do not adapt to the status quo stop talking to them or leave to find more exciting work elsewhere.

To cope with bureaucratic minds the best thing to do is to seem to agree while ignoring and avoiding all signs of rebelliousness. One can be amused by their machinations and contradictions while being agnostic about it all. Do not share this with less ironic minds.

Bureaucratic minds do change. This happens rapidly after years of monolithic behaviour. Prepare for the change by having a new plan ready. Then one can be at the leading edge and your plan can be adopted.

It is worthwhile seeing the defects of a situation and prepared to solve the problem with a new plan at short notice.

Surgeons and bureaucrats are different people. Each need each other but cannot convince the other of anything as their basic principles and psyches are different.

They should mutually ignore each other, live together and keep out of each other's way until the time of rapid change occurs.

John R Taylor 